\title{
O uso de Realidade Virtual, Aumentada e Misturada no Jornalismo Impresso Brasileiro ${ }^{1}$
}

\author{
Alessandra de Falco² \\ Silvia Cristina dos Reis ${ }^{3}$
}

Resumo: A presente pesquisa traz os resultados da análise realizada nos jornais Estadão, O Globo e na revista Veja no mês de outubro de 2015 e maio e junho de 2016, sobre o uso de Realidade Virtual, Aumentada e Misturada como técnicas empregadas para ampliar o conteúdo do jornalismo impresso. Foi investigado como os veículos citados se utilizaram desse recurso nas suas versões impressas. A análise mostrou que, nos veículos em questão, os usos de conteúdos usando a técnica da Realidade Virtual, Aumentada e Misturada não explora suas potencialidades, como por exemplo, atualizar o conteúdo impresso com dados novos, ou é inexistente.

Palavras-chave: Jornalismo Imersivo. Realidade Virtual. Realidade Aumentada. Realidade Misturada. Jornalismo Impresso Brasileiro.

Resume: The present research brings the results of the analysis carried out in the newspapers Estadão, O Globo and Veja magazine in the month of October of 2015 and May and June of 2016, on the use of Virtual Reality, Augmented and Mixed as techniques used to extend the content of the printed journalism. It was investigated how the cited vehicles used this feature in their printed versions. The analysis showed that, in the vehicles in question, the use of content using the Virtual Reality, Augmented and Mixed technique does not exploit its potentialities, such as updating the printed content with new data or is non-existent.

Palavras-chave: Immersive Journalism. Virtual Reality. Augmented Reality. Mixed Reality. Brazilian printed journalism.

Resumen: La presente investigación trae los resultados del análisis realizado en los diarios Estadão, O Globo y en la revista Veja en el mes de octubre de 2015 y mayo y junio de 2016, sobre el uso de Realidad Virtual, Aumentada y Mixta como técnicas empleadas para ampliar el contenido del periodismo impreso. Se investigó cómo los vehículos citados se utilizaron de ese recurso en sus versiones impresas. El análisis mostró que, en los vehículos en cuestión, los usos de contenidos usando la técnica de la Realidad Virtual, Aumentada y

'Trabalho apresentado no XXIII Seminário de Iniciação Científica da Universidade Federal de São João del-Rei.

${ }^{2}$ Formada em Jornalismo na PUC-Campinas e na Unicamp fez Letras, especialização em Jornalismo Científico e doutorado em Educação. É mestre e terminou o estágio Pós-Doutoral na Metodista-SP. Tem experiência profissional e acadêmica na área de Jornalismo Cientifico e Tecnológico. Na UFS é docente de Ciberjornalismo na Graduação e na Pós-Graduação no NEAD e no PIPAUS. 3Ppossui graduação em Letras pela Universidade Federal de São João del-Rei (UFSJ). Concluiu o curso de Jornalismo também na UFSJ, onde foi bolsista do Programa VAN-Educomunição, trabaIho premiado com Menção Honrosa pela universidade. Atou como bolsista de Iniciação Científica - PIBIC/CNPq. É membro do Grupo de Estudos \&amp; Pesquisas em Educomunicação, certificado pelo CNPq. 
Mixta no explora sus potencialidades, como por ejemplo, actualizar el contenido impreso con datos nuevos o es inexistente.

Palabras clave: Periodismo de Inmersión. Realidad Virtual. Realidad Aumentada. Realidad Mixta. Periodismo brasileño Impreso.

\section{Introdução}

Os diferentes aparatos tecnológicos, que surgiram ao longo dos anos, por exemplo o computador, mudaram a forma de interação entre as pessoas. Para Kirner e Siscoutto (2007, p. 03) "[...] o computador eletrônico trouxe um novo processo sofisticado de interação com as aplicações, exigindo conhecimento simbólico (abstrato) e necessidade de treinamento, uma vez que o conhecimento do mundo real já não era suficiente".

Dentre as possibilidades abertas pela informática vimos desde a década de 80 o uso de Realidade Virtual, Aumentada e Misturada. De maneira resumida, a Realidade Virtual (RV) é uma '[...] interface avançada do usuário para acessar aplicações executadas no computador, propiciando a visualização, movimentação e interação do usuário, em tempo real, em ambientes tridimensionais gerados por computador" (KIRNER, SISCOUTTO 2007, p. 07). Já a Realidade Aumentada (RA), conforme definem Azuma et al (apud LUCENA, 2012, p. 27) é "[...] toda a tecnologia que permite a combinação de dados reais e virtuais no ambiente, opera interativamente, em tempo real, e de maneira que esses dados fiquem em registro (alinhados)". E a Realidade Misturada (RM), como próprio nome sugere é a mistura de realidades.

Kirner e Siscoutto (2007, p. 05) afirmam que foi "[...] a evolução tecnológica que propiciou, na década de 90, o aparecimento da RA que [...] vem sendo considerada uma possibilidade concreta de vir a ser a próxima geração de interface popular, a ser usada nas mais variadas aplicações em espaços internos e externos".

Já a Realidade Virtual (RV) ganhou destaque em meados dos anos 80, e o desenvolvimento desses dois tipos de realidades possibilitou o aparecimento da Realidade Misturada (RM). Ademais, esses conceitos possibilitam novas formas de comunicar, por exemplo, o Jornalismo de Imersão (MARTIN, 2015; SANTOS, 2016; De LA PEÑA, 2010). A presente pesquisa teve como principal objetivo explicar os termos supracitados e apresentar os dados e análise do estudo realizado sobre os usos desses recursos pela revista Veja e pelos jornais Estadão e 0 Globo em seu conteúdo informativo, sendo que a escolha por esses veículos deve-se ao fato de estarem entre os de maior circulação no país.

A Veja, segundo dados do Instituto Verificador de Comunicação (IVC) presente em seu mídia kit de janeiro de 2017, possui uma circulação total 1.030.089 exemplares semanais. A revista geralmente traz 17 seções em cada exemplar impresso - algumas aparecem em todos os exemplares, por exemplo, Índice e Veja Recomenda, e outras, como Imagem da semana, Datas e etc. não são fixas, ou seja, não estão presente em todas as edições

Já o jornal impresso o Globo e o Estadão estão entre os cinco veículos de maior circulação no país, segundo dados do IVC, no primeiro semestre 2015, com tiragem média de 320.374 e 250.045 exemplares, respectivamente. O jornal O Globotem 11 editorias - O País, Rio, Opinião, Economia, Mundo, Segundo Caderno, Jornais de Bairro, Sociedade, Esporte, Boa viagem e Ella -, já o Estadão possui 16 cadernos - $7^{0}$ Caderno, Economia e Negócios (E\&N), Caderno 2, Edição de Esportes, Jornal do Carro, Estadão PME, .Edu, Viagem, Paladar, Divirta-se, Aliás e Casa, Jornal do Carro (classificados), Empregos \& Carreiras, Imóveis (classificados), Oportunidades (classificados). 


\section{Percurso metodológico}

Essa pesquisa ampara-se no Estudo de Caso sobre o uso dos recursos de Realidade Virtual, Realidade Aumentada e Realidade Misturada no fazer jornalístico brasileiro. Para tanto, foi realizada a análise de todos os exemplares dos jornais O Globo e Estadão e da revista Veja do mês de outubro de 2015. Na revista Veja foi feito novo recorte, isso porque os dados coletados nos 4 exemplos analisados em outubro de 2015 não apresentavam a aplicação dos recursos estudados (RA ou RV ou RM), mas, a partir de maio 2016, a revista começou a usar a RA em suas publicações, o que justifica o recorte feito em maio e junho de 2016.

Após a seleção do preliminar do material, iniciou-se a parte de coleta de dados propriamente dita, ou seja, cada jornal e revista foi analisado, página por página e coletadas informações especificando a editoria em que apareciam os recursos de realidades Virtual, Aumentada e qual a frequência, com o intuito de definir se usavam ou não os recursos pesquisados e em que editoria.

A pesquisa foi norteada pelos seguintes questionamentos: Questão principal: Como os recursos de Realidade Virtual, Aumentada e Misturada são usados no jornalismo impresso no Brasil? Tal questionamento teve como questões secundárias perguntas sobre Em que caderno aparecem os recursos com mais frequência (esporte, cultura, política, etc.) e por que eles são usados em determinada editoria e não em outra?

A opção pela metodologia de Estudo de Caso deve-se ao fato do objeto de análise ser um fenômeno contemporâneo passível de observação direta, pois, de acordo com Yin (2010, p. 39), o Estudo de Caso trata-se de "[...] uma investigação empírica que investiga um fenômeno contemporâneo em profundidade e em seu contexto de vida real".

Além disso, foi utilizada como técnica a Análise de Conteúdo que, segundo Bardin (2011. p. 38): "[... é a inferência de conhecimentos relativos às condições de produção (ou eventualmente, de recepção), inferência esta que recorre a indicadores (quantitativos ou não)". Este tipo de análise tornou-se possível a partir de suposições a respeito da ocorrência e frequência do uso de recursos de RV, RA e RM nos produtos midiáticos em questão.

E, ainda, para a análise dos dados coletados fez-se necessário uma revisão bibliográfica junto a artigos, projetos de pesquisas, livros e documentos de estudiosos dos assuntos pesquisados, além do acesso a websites para contextualizar o cenário, auxiliar na interpretação dos conteúdos previamente selecionados e fundamentar teórica e cientificamente os resultados alcançados.

Primeiramente foi realizado o levantamento bibliográfico dos assuntos e fichamento dos textos mais relevantes. Em seguida, fez-se o levantamento dos exemplares de jornais e revistas que utilizaram os recursos de RV, RA e RM em conteúdos jornalísticos, em outubro de 2015 e de maio a junho de 2016. Foi feito o recorte de apenas um mês por acreditar ter uma amostragem já que os jornais são diários e por entender 4 edições que um veículo semanal (a revista) seria suficiente para averiguar se havia ou não o emprego destes recursos por estes veículos.

Depois, foi feita uma análise e investigação sobre a forma como os recursos foram usados nos veículos estudados e em quais cadernos (esporte, cultura, política, etc.) eles estavam mais presentes, para, finalmente, responder às questões principal e secundárias. Enfim, a pesquisa proposta teve como objetivo investigar e analisar o uso ou não dos recursos de RV, RA e RM, nos conteúdos informativos, por jornais e revista brasileiros, em suas versões impressas e produzir conteúdo teórico sobre o assunto. 


\section{A relação da pesquisa com o conceito de Jornalismo Imersivo}

O jornalismo imersivo (JI) possui inúmeras definições, muitas delas ambíguas e contraditórias, devido a proximidade existente entre esta e outras modalidades de jornalismo, por exemplo, jornalismo investigativo (PEDRERO; ASENSIO, 2014, p. 02). Para Hidalgo e Barrero (apudPEDRERO; ASENSIO, 2014, p. 03) o jornalismo de imersão é aquele no qual o jornalista vivencia, ou seja, participa da vida social que vai retratar. É possível afirmar, em tal contexto, que o conteúdo produzido é mais abrangente e rico de detalhes. Além disso, os diversos recursos tecnológicos existentes podem levar ao público, não apenas a sensação da veracidade dos fatos, mas também a sensação de estar no local em que tudo acontece, pois, segundo Martin (2015, p. 414)

O áudio interativo e imersivo, o vídeo e a fotografia em 360 graus, as câmaras web, e o vídeo e a fotografia em três dimensões ou a realidade aumentada ofereciam caminhos de exploração para o relato jornalístico e aumentavam a sensação de exploração de um lugar (tradução nossa).

Sendo assim, o Jl pode ser entendido como aquele em que, de alguma forma, o jornalista ou o público, ou mesmo ambos, entram, aprofundam-se no assunto retratado, seja como emissor que vivencia os fatos e procura buscar os diversos ângulos do assunto, seja como receptor que tem a impressão de estar no local do acontecimento

Para Brasil e Frazão (2014, p. 128), " [...] trata-se de uma proposta de abordagem e produção na qual o jornalista 'mergulha' nos fatos e eventos". No entanto, na concepção dos autores, o público também desempenha papel importante. Isso porque, conforme explicam, "[... o telespectador 'participa' da produção e da transmissão das notícias e das coberturas pelas redes sociais, indicando pautas, expondo opinião a respeito dos fatos reportados [...]" (BRASIL, FRAZ̃̃O, 2014, p. 128)

Dessa forma, o receptor, não obtém a informação de forma passiva, mas sim reage e ajuda na produção de conteúdo, passando a exercer um papel ativo perante os fatos. 0 pesquisador Márcio Carneiro dos Santos (2016, p. 01), que se dedica ao estudo do impacto das novas mídias no Jornalismo, relata que:

A interconexão de pessoas nas plataformas de mídias sociais e sua capacidade de gerar conteúdo em diversos espaços da internet têm ajudado a construir um ecossistema próprio de expressão e sociabilidade, mas também representado um desafio para o modelo de negócio sobre o qual se apoiam as empresas tradicionais de mídia que hoje enfrentam o grave problema da fragmentação das audiências e da progressiva perda de controle e influência, diluída pela multiplicação dos canais de emissão.

De modo que a possibilidade de mudança para essa situação está relacionada à busca por inovações (SANTOS, 2016, p. 22). Sendo assim, o J surge como uma possibilidade para atrair o público mais antenado, ou seja, aquele conectado com os novos aparatos tecnológicos. Isso porque esse tipo de jornalismo utiliza tanto de recursos narrativos, quanto visuais 
que privilegiam a primeira pessoa e, dessa forma, despertam maior identificação e aproximação do público. Porém, Santos (2016, p. 191) ainda esclarece que:

[...] a transformação não pode ser avaliada apenas pelo seu vetor tecnológico. Por isso, para justificar esse modelo, precisamos também considerar fatores culturais e econômicos [...] estudos já demonstram que o consumo de algumas mídias tradicionais, como os jornais impressos e as revistas, vem caindo, ao mesmo tempo em que o uso de meios digitais tem crescido.

Daí a necessidade de um modelo de jornalismo que atenda aos futuros consumidores de informação, cujo modelo atual não desperta mais tanto interesse. Neste cenário, a concepção de $\mathrm{J}$ de De La Peña et al (2010, p. 01) está vinculada a liberdade que o público tem de participar/entrar virtualmente no local dos fatos, através de avatares digitais que proporcionam a impressão de vivenciar os acontecimentos.

Já Rodrigues (2013, p. 97), explica que "[...] no contexto das mídias digitais, as narrativas multimídia configuram-se como uma modalidade que têm explorado formatos jornalísticos inovadores", como os newsgamese o próprio JI, cuja ideia fundamental, de acordo com Alzamora e Tárcia (apud CORRÊA, 2014, p. 107), "[...] seria permitir ao participante entrar em um cenário representativo da história, criado virtualmente".

Além disso, nesse tipo de jornalismo, o público tem diferentes perspectivas e interage com o assunto retratado. Entretanto, o objetivo desta abordagem não é simplesmente representar determinada situação, mas proporcionar a possibilidade de experimentação dos fatos (DE LA PEÑA et al apud JENNER, 2014, p. 03). Ou seja, o público tem a possibilidade de ver diferentes ângulos de um fato. Entretanto vale ressaltar que estes ângulos foram predefinidos pelo emissor.

\section{Realidade Virtual, Aumentada e Misturada}

Apesar de o artista e cientista da computação Jaron Lanier ter cunhado o termo Realidade Virtual no final dos anos de 1980, segundo Kirner e Tori (2004, p. 03) "[...] as primeiras propostas e os primeiros resultados que alicerçaram a Realidade Virtual surgiram bem antes". Já no final da década de 1960, foi produzido, por Ivan Sutherland, "[...] o primeiro capacete de realidade virtual, precursor de uma série de pesquisas e desenvolvimentos" (KIRNER; TORI, 2004, p. 03).

Acerca da temática Kirner e Siscoutto (2007, p. 08) explicam que:

A interface baseada em realidade virtual permite que habilidades e conhecimento intuitivos do usuário possam ser utilizados para a maTnipulação dos objetos virtuais. Esse tipo de interação é realizado, através de dispositivos não convencionais, como capacete de visualização ou luvas, o próprio corpo, como gestos e comandos de voz, ou até mesmo dispositivos convencionais como mouse, teclado e monitor de vídeo.

Tal situação ocorre de maneira com que o usuário tenha a sensação de "[... estar atuando dentro do ambiente virtual", na RV o usuário tem a impressão de ter sido transportado para o mundo virtual. Para Kirner e Siscoutto (2007, p. 08), a interação com o virtual acontece de fato "[...] quando o usuário entra no espaço virtual das aplicações e visualiza, explora, manipula e aciona ou altera os objetos virtuais, usando seus sentidos, incluindo os movimentos tridi- 
mensionais de translação e rotação naturais do corpo humano". Sendo assim, a realidade virtual "[...] é um paradigma pelo qual usa-se um computador para interagir com algo que não é real, mas que pode ser considerado real enquanto está sendo usado" (HANCOCK apud VALEIRO NETTO; MACHADO; OLIVEIRA, 2002, p. 05). Ou seja, a RV é real para o usuário durante o tempo que ele a utiliza. É o que ocorre, por exemplo, nos projetos de Jornalismo de Imersão, quando o público se vê no ambiente de determinado acontecimento. Apesar de estar em um ambiente de realidade virtual, no momento de imersão, o usuário vivencia o fato, sejam pelas imagens, sons, entre outros sentidos, que the proporcionam sensação de estar de fato naquele local. Pode-se resumir que "RV é a forma mais avançada de interface do usuário com o computador até agora disponível" ((HANCOCK apud VALEIRO NETTO; MACHADO; OLIVEIRA, 2002, p. 05).

Os autores Valeiro Netto, Machado e Oliveira (2002, p. 05) comparam a RV a um "[...] espeIho da realidade física", isso porque, segundo os autores, na RV o "[...] indivíduo existe em três dimensões". A Realidade Virtual, assim como a Realidade Aumentada, apesar de terem sua origem em meados do século passado, ainda são pouco exploradas no mercado editorial. Entretanto esses campos têm auxiliado na interação entre homem e máquina.

Ainda segundo Kirner e Siscoutto (2007, p. 19) a RV e a RA proporcionam:

[...] aos usuários, melhores condições de interação com aplicações computacionais propiciando a eles interações naturais e potencialização de suas capacidades. Para isso, muitos recursos são utilizados, envolvendo hardware, software, periféricos, redes, tecnologias especiais, técnicas de projeto e avaliação e o desenvolvimento de aplicações.

Os autores comparam estes recursos de modo a facilitar o entendimento das suas especificidades e diferir uma da outra. Para eles a RA se distingue da RV da seguinte maneira:

[...] a realidade aumentada enriquece a cena do mundo real com objetos virtuais, enquanto a realidade virtual é totalmente gerada por computador; no ambiente de realidade aumentada, o usuário mantém o sentido de presença no mundo real, enquanto que, na realidade virtual, a sensação visual é controlada pelo sistema; a realidade aumentada precisa de um mecanismo para combinar o real e o virtual, enquanto que a realidade virtual precisa de um mecanismo para integrar o usuário ao mundo virtual. (KIRNER; SISCOUTTO, 2007, p. 11)

Sendo assim, pode-se dizer que para os autores na RA existe uma mistura do virtual com o real, a medida em que objetos sintéticos são projetados no ambiente real e há um diálogo com elementos reais. Além disso, como na RA existe a sobreposição de objetos sintéticos no ambiente real do usuário, as interações são mais fáceis e naturais, e não necessitam necessariamente do uso de equipamentos especiais.

Já a RV "[...] depende de equipamentos de visualização, como monitor, projetor e capacete, normalmente utilizados em ambientes fechados" (KIRNER; SISCOUTTO, 2007, p. 05), o que, por enquanto, ainda dificulta sua difusão. Cabe ressaltar que a tecnologia de RA data do ano de 1968, quando Ivan Sutherland, engenheiro elétrico formado pela Carnegie Institute of Technology, inventa o dispositivo Head Mounted Display, ou HMD, que ainda hoje é visto como o marco dessa tecnologia.

De acordo com Azuma (1997, p. 02), para haver RA é necessário que exista uma "[...] com- 
binação entre o mundo real e virtual, que a interação seja em tempo real e em registro em 3D". Já para Magni (2015), a RA é um dos transformadores da experiência imagética, pois através do Google Glass, por exemplo, é possível fazer a sobreposição de informações textuais projetadas na interface à frente das imagens móveis, de modo que a imagem pode vir carregada de dados até então invisíveis ou inacessíveis.

Nesse sentido, a fotografia não é mais só o que está dentro do quadro, pois além do Google Glass, dispositivos com leitores de RA podem levar o leitor/observador não apenas para a imagem do entorno do quadro fotografado, como para a localização ou textos, sons e vídeos do momento em que a imagem foi capturada, agregando informação ao trabalho do jornalista.

Conforme explicam Silva e Rodrigues (2013, p. 80), "[...] a Realidade Aumentada se configura como recurso contextual valioso para o jornalismo e com inúmeras aplicações para a produção e o consumo", como por exemplo, sobreposições de informações e possibilidade de atualização dos conteúdos após seu deadline. Além disso, derruba a ideia de que no impresso o espaço é finito, ao contrário da web, já que, através da sobreposição de camadas é possível agregar mais informações às notícias, como por exemplo, vídeos, áudio, websites etc., tornando-as mais interessante.

E assim, não apenas mantém o público existente, mas conquista as novas gerações que estão mais conectadas e abertas às inovações tecnológicas. O que pode significar, não apenas a conquista de novos leitores, mas a sobrevivência do impresso num mundo cada vez mais tecnológico. Neste cenário, a Realidade Misturada (RM), como o próprio nome sugere é um mistura de realidades. Nela é feita uma combinação de aspectos da RV, de modo que o usuário possa transitar entre o mundo real e o virtual.

O recurso de RM torna possível ampliar informações sobre o espaço físico, através mobile tagging, que pode ser definido como ".... the process of scanning, decoding and reading out the content of a $2 d$ barcode by using a camera of a mobile device. Various types of information can be saved in the code"(MOBILE TAGGIN BLOG, 2007). Gabriel (2010, p. 35) explica que "[...] por detrás do mobile tag está a ideia de uma convergência absoluta de mídia e informação, pois as tags conectam suportes documentais estáticos com a Internet e encorajam o comportamento interativo das pessoas".

\section{Dados e análise}

A revista Veja e o jornal Estadão não apresentaram, no mês de outubro de 2015, nenhum dos recursos citados em seu conteúdo jornalístico. Apenas na parte de publicidade ocorreu o uso do QR Code - Quick Response Cod, um código bidimensional fácil de ser lido por scanners - , entretanto o objetivo da presente pesquisa é somente os conteúdos de cunho informativo. No entanto, o que foi possível perceber é que esses meios de comunicação, principalmente o jornal Estadão, trouxeram em várias notícias links para que o leitor acompanhasse o assunto ou obtivesse mais informações nos sites dos respectivos veículos.

Entretanto, para visualizar as informações trazidas por esses links era necessário digitá-los no navegador, ou seja, não havia nenhum aplicativo capaz de lê-los e levar o usuário direto à página onde estava a informação. Já o jornal o Globo também apresentou muitos links em suas matérias, similares aos que apareceram na revista Veja e no jornal Estadão, porém, em uma matéria da editoria Sociedade, cujo tema era o ENEM (Exame Nacional 
do Ensino Médio) e na editoria RioShow, que traz a agenda cultural do Rio de Janeiro, foi usado o QR code. Porém, esse recurso foi usado apenas como forma de direcionar o leitor ao gabarito da prova, no primeiro caso e, no segundo, para levar o usuário à página de O Globona web, que continha à agenda cultural.

Os dados coletados e as observações feitas durante a análise do corpus (coletado em outro de 2015) mostram que os veículos em questão não fazem uso dos recursos de RV, RA e RM, como foi o caso da revista Veja e do jornal Estadão, ou utilizam de forma bem limitada como aconteceu com O Globo.

Outro ponto importante a ser observado nesses veículos de comunicação é que em nenhum dos casos o uso do QR Code serviu para manter os conteúdos atualizados, ou acrescentar novos dados, por exemplo, informações atualizadas do fato em questão. O QR Code se justifica apenas como forma de ampliar o espaço restrito do impresso. O que não deixa de ser importante, uma vez que os custos com impressão são bem significativos.

Cabe ressaltar, contudo, que a pesquisa indicou que em maio de 2016, a revista Veja decidiu inovar, através do uso do aplicativo Blippar, que conforme explica Vieira (2016) é um aplicativo de RA para Android criado para usuários interagirem com produtos. Este app é capaz de levar a sites, vídeos, entre outros, de modo que o usuário possa saber mais detalhes do conteúdo das publicações.

De acordo com matéria publicada no site da Veja, a revista entrou de fato no mundo virtual através do MV (Mobile View), nome dado ao novo recurso a partir do qual o usuário acessa conteúdo virtual pelo celular. A revista explica que é muito simples e prático usar o MV, basta apontar a câmera do smartphone para a imagem da revista que o usuário tem acesso ao conteúdo virtual. O que justificou um novo recorte.

Apesar da parte de coletas de dados dessa pesquisa ter sido encerrada em outubro de 2015, optou-se por esse novo recorte direcionado, apenas, à revista Veja, devido às informações supracitadas. Deste modo foram analisadas 4 edições da revista entre os meses de maio e junho de 2016. Nesse novo corpus de análise foi possível perceber que de fato a Veja está usando os recursos de RA, porém no recorte do mês de outubro de 2015 (4 edições), a revista não fez uso de nenhum dos recursos pesquisados.

Em cada edição houve uma média de 12 conteúdos em que o MV foi usado. As editorias que mais apresentaram o MV foram a de Cultura, Tecnologia e Política, respectivamente (Figura I), sendo que na Cultura, o MV está presente em todas as edições observadas, e mais de uma vez, provavelmente porque nessa editoria há sempre lançamentos de filmes, livros ou CDs. Os conteúdos trazidos pelo MV variaram entre áudios (conversa entrevista e música), texto (trecho de um livro, texto, entrevista), vídeos (trailer, vídeos cenas de filmes, clipes) e fotos. 
Figura I - Distribuição das editorias e o uso de Mobile View

\section{Edições 2479 -2482 (mai./jun.)}

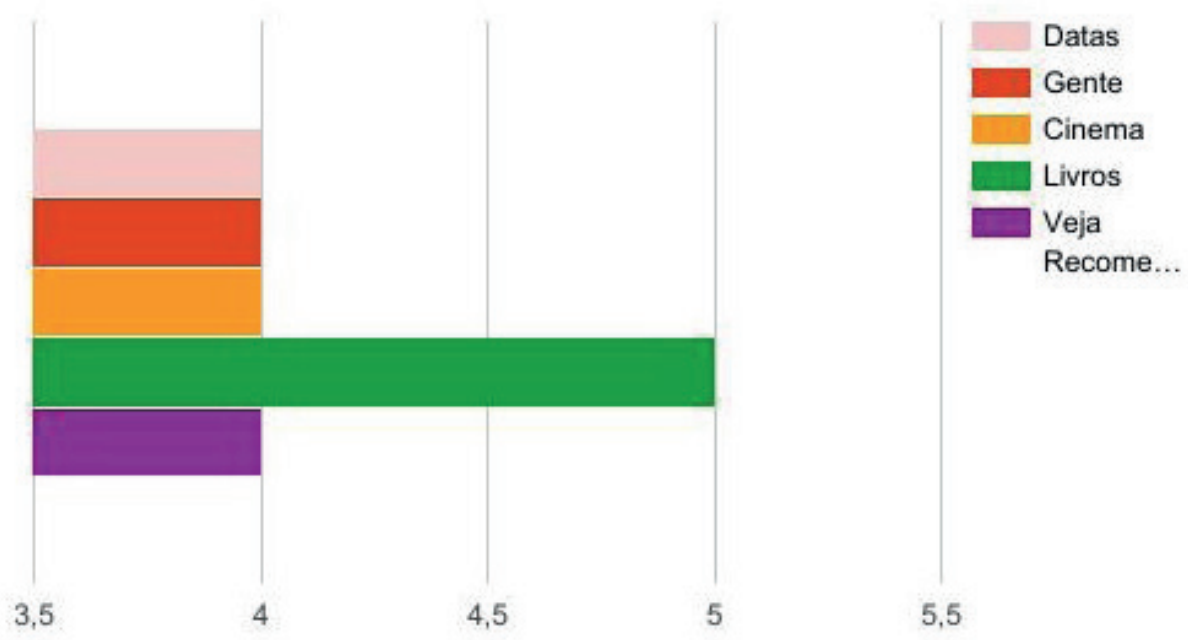

Seções X Mobile View

A utilização do MV, na maioria dos casos, serviu para agregar informações audiovisuais ao texto escrito e torná-lo mais atraente ou, simplesmente, trouxe o áudio do texto escrito. Nesse último caso, uma das utilidades dessa forma de inovar é que o usuário não precisa parar para folhear a revista, ou seja, pode fazer outra atividade, por exemplo, exercícios físicos, enquanto se informa a partir do conteúdo de áudio trazido pela revista.

Outra vantagem é a inclusão de deficientes visuais, uma vez que estes podem ter acesso ao conteúdo através do áudio e não há a necessidade de alguém para fazer a leitura. Já quando o MV traz parte do texto de livros, trailer de filmes ou a música de uma banda ou cantor, isso não só torna o texto mais atraente, como pode aguçar a curiosidade do leitor para conhecer mais sobre o assunto. Além disso, como afirma os autores "[...] A "presença" da informação misturada ao ambiente real fornece enriquecimento ao conteúdo informativo de relevância social, possibilitando ao jornalismo continuar pertinente e importante na atual sociedade conectada" (LIMA JUNIOR; BAZAN, 2013, p.38).

Enfim, os recursos de RA usados pela Veja podem significar o início de uma nova Era para a revista e até mesmo para o impresso como todo. Entretanto, pode ser algo passageiro, uma vez que, conforme descreve Silva e Rodrigues (2013, p. 79), durante a Copa do Mundo de 2010, a Veja utilizou o QR Code na edição especial sobre a Copa, mas, depois disso, levando em consideração os dados de outubro de 2015 dessa pesquisa, o uso do recurso se restringiu a parte publicitária do veículo.

Além disso, comparando os dados foi possível perceber que, a partir da edição 2479, o MV foi apresentado até o último exemplar analisado, edição 2482, mas a frequência do recurso diminuiu 30,76\%. A editoria que manteve o MV com a mesma frequência foi a de Cultura, provavelmente por envolver infotenimento a partir de recursos audiovisuais.

Outro ponto observado é que em nenhuma das vezes que o MV apareceu foi para atualizar o conteúdo do impresso, ou seja, a revista não parece ter interesse em manter o conteúdo impresso atualizado com novas informações. Isso porque em todos os casos 
em que o MV foi usado, ele apenas reforçou as informações existente através de fotos, áudio, vídeos, entre outros

\section{Conclusão}

O propósito dessa pesquisa era mostrar se e como os jornais O Globo, Estadão e a revista Veja faziam uso dos recursos de Realidade Virtual, Aumentada e Misturada em seu conteúdo informativo. Entretanto, durante a coleta de dados percebeu-se que os veículos em questão não usavam os recursos ou faziam isso de forma muito limitada. Sendo assim, o corpus de análise foi estendido e houve uma ênfase maior na Revisão bibliográfica, isso porque percebeu-se que não existia uma literatura abrangente e disponível de forma unificada sobre o tema em questão.

Além disso, foi acrescentado no referencial teórico da pesquisa o assunto Jornalismo Imersivo ou de Imersão, devido ao fato dessa forma de fazer jornalismo estar intimamente ligada aos recursos de RV, RA e RM, e também porque este é outro assunto que está sendo bastante explorado no Ciberjornalismo. Assim, esta pesquisa colaborou com o levantamento da literatura sobre os temas citados.

Ademais, a análise dos veículos impressos mostrou que, apesar de a mídia recentemente recorrer à abordagem de uso desses recursos no fazer jornalístico, o que se vê nos três veículos de grande circulação no Brasil, é que aqui esses recursos ainda não fazem parte da prática jornalística efetivamente, isso porque apenas a revista apresentou o recurso de RA, no recorte de maio e junho de 2016.

\section{Referências}

AZUMA, R. T. A survey of augmented reality. Presence: Teleoperators and virtual environments, 1997, v. 6, n. 4, p. 355-385. Disponivel em: <http://citeseerx.ist.psu.edu/viewdoc/download?doi=10.1.1.35.5387\&rep=rep 1\&type=pdf> Acesso em: 02 abr. 2016.

BARDIN, L.. Análise de Conteúdo. São Paulo: Edições 70, 2011.

BRASIL, A.; FRAZÃO, S. M. Drones no ar e ninjas nas ruas: os desafios do jornalismo imersivo nas mídias radicais. Sessões do Imaginário, v. 18, n. 30, p. 127-136, 2014. Disponível em: <http://revistaseletronicas.pucrs.br/ojs/index.php/famecos/article/viewArticle/15972>. Acesso em: 02 mai. 2016.

CORRÊA, E. CD. A narrativa transmídia como estratégia de incentivo à leitura. Texto Digital, v. 10, n. 2, 2014, p. 98-113. Disponível em: <https://periodicos.ufsc.br/index.php/textodigital/ article/viewFile/1807-9288.2014v10n2p98/28395>. Acesso em: 10 mai. 2016.

SILVA, F. F:; RODRIGUES, A. A. Interações analógico-digitais móveis na mídia impressa: camadas informacionais na narrativa com QR code, aurasma e realidade aumentada. Rizoma 2013, 1(1), pp. 71-84. Disponível em: <https://www.academia.edu/4599764/Intera\%C3\%A7\%C3\%B5es_anal\%C3\%B3gicodigitais_m\%C3\%B3veis_na_m\%C3\%Addia_impressa_camadas_ informacionais_na_narrativa_com_QR_Code_Aurasma_e_Realidade_Aumentada>. Acesso em: 21 mar. 2015 
DE LA PEÑA, N. et al. Immersive journalism: immersive virtual reality for the first-person experience of news. Presence: Teleoperators and Virtual Environments, v. 19, n. 4, p. 291-301, 2010. Disponível em: <http://www.mitpressjournals.org/doi/pdf/10.1162/PRES_a_00005> Acesso: 29 abr. 2016.

GABRIEL, M. QR codes \& Realidade Aumentada. Slideshare. Disponível em: < <http://pt.slideshare.net/marthagabriel/qr-codes-realidade-aumentada-por-martha-gabriel>. Acesso em: 18 jun. 2016.

JENNER, Ch. Navigating distant worlds: International development and social change in interactive web documentary. Glocal Times, 2014, n. 20. Disponível em: <http://130.241.16.45/ ojs/index.php/gt/article/view/2870>. Acesso em: 30 abr. 2016.

KIRNER, C.; SISCOUTTO, R. A. Fundamentos de Realidade Virtual e Aumentada. In: Realidade Virtual e Aumentada: Conceitos, Projeto e Aplicações. Porto Alegre: Editora SBC-Sociedade Brasileira de Computação, 2007. Disponível em: <http://www.de.ufpb.br/ labteve/ publi/2007_svrps.pdf>. Acesso em: 20 nov. 2015.

; TORI, R. Introdução à realidade virtual, realidade misturada e hiper-realidade. Realidade Virtual: Conceitos, Tecnologia e Tendências. São Paulo, 2004, v. 1, p. 3-20. Disponível em: <http://ckirner.com/download/capitulos/livro_pre_simp-2004.pdf\#page=12>. Acesso em: 18 abr. 2016.

LIMA JUNIOR, W. T.; BAZAN, R. Jornalismo Hiper-Real: narrativa jornalística e relações cognitivas frente às tecnologias de Realidade Aumentada. Líbero, São Paulo, v. 16, n. 37, p. 29-40, jan./jun. de 2013. Disponível em: <https://www.researchgate.net/publication/258092696_Jornalismo_HiperReal_narrativa_jornalistica_e_relacoes_cognitivas_frente_as_tecnologias_de_ Realidade_Aumentada>. Acesso em: 29 mar. 2016.

LUCENA, B. F.. Realidade Aumentada em celulares: um estudo sobre a tecnologia e seus potenciais [Dissertação de Mestrado]. Pontifícia Universidade Católica do Rio de Janeiro, Departamento de Artes e Design, Rio de Janeiro, 2012. Disponível em: <https://www.academia. edu/4074282/Dissertação_de_Mestrado>. Acesso em: 28 mar. 2015.

MAGNI, L. F.. Novas linguagens visuais em tecnologias wearables: uma análise da fotografia produzida no Google Glass. Jornadas de Sociologia: Coordenadas contemporáneas de la sociología: tiempos, cuerpos, saberes, Buenos Aires, 2015. Disponível em: <http://jornadasdesociologia2015.sociales.uba.ar/wp-content/uploads/ponencias/1088_95.pdf>. Acesso em: 11 nov. 2015.

MARTIN, E. D. Periodismo inmersivo o cómo La la realidad virtual y el videojuego influyen en la interfaz e interactividad del relato de la actualidad. El profisional de la información, v. 24, n. 4, jul./ago. 2015. Disponível em: <https://www.academia.edu/14283741/Periodismo_inmersivo_o_c\%C3\%B3mo_la_realidad_virtual_y_el_videojuego_influyen_en_la_interfaz_e_interactividad_del_relato_de_actualidad>. Acesso: 24 mai. 2016. 
MOBILE TAGGIN BLOG. What is Mobile-Tagging, 2007. Disponível em: <http://mobile-tagging. blogspot.com.br/2007/09/what-is-mobile-tagging.html>. Acesso em: 18 jun. 2016

PEDRERO, M. T. C.; ASENSIO, A. C. Estudio histórico, textual y procedimental sobre el Periodismo de Inmersión [Trebau Fi de Grau]. Universitat Autonoma de Barcelona, Facultat de Ciènces de la Comunicación, 2014. Disponível em: <http://ddd.uab.cat/pub/tfg/2014/131451/ Maite_Cabezas.pdf>. Acesso em: 29 abr. 2016

RODRIGUES, A. A. Jornalismo e educomunicação: a produção de narrativas multimídia no ensino-aprendizagem. Revista Mediação, v. 15, n. 17, 2013. Disponível em: <http://www.fumec br/revistas/mediacao/article/view/1852/pdf>. Acesso em: 10 mai. 2016.

SANTOS, M. C. Jornalismo e internet das coisas: o modelo de jornalismo de imersão. São Luís: LABCOM DIGITAL, 2016, p. 179-201.

Internet das Coisas e sistemas inteligentes no jornalismo: o conceito de presença diluído entre as narrativas da complexidade urbana. Comunicação \& Inovação, v. 17, n. 34, p. 21-39, 2016. Disponível em: <http://seer.uscs.edu.br/index.php/revista_comunicacao_inovacao/article/view/3769/1961>. Acesso em: 10 ago. 2016.

VALEIRO NETTO, A.; MACHADO, L. S.; OLIVEIRA, M. C. F. Realidade Virtual: Definições, Dispositivos e Aplicações. Tutorial. Revista Eletrônica de Iniciação Científica da SBC, II, 2002, v. 2. Disponível em: <http://www.di.ufpb.br/ liliane/publicacoes/2002_reic.pdf>. Acesso em: 18 abr. 2016.

VIEIRA, L. Aplicativo de realidade aumentada para jogar, ouvir músicas, assistir vídeos e muito mais. Techtudo, 17/03/2015. Disponivel em: <http://www.techtudo.com.br/tudo-sobre/blippar.html>. Acesso em: 08 ago. 2016.

YIN, R. K. Estudo de caso: Planejamento e métodos. Porto Alegre: Bookman, 2010. 